\section{Colegiados de gestão em serviços de saúde: um estudo empírico}

\author{
Management committees in health services: \\ an empirical study
}

Luiz Carlos de Oliveira Cecilio ${ }^{1}$

\footnotetext{
${ }^{1}$ Faculdade de Medicina, Universidade Federal de São Paulo, São Paulo, Brasil.

Correspondência L. C. O. Cecilio Departamento de Medicina Preventiva, Faculdade de Medicina, Universidade Federal de São Paulo. Rua Borges Lagoa 1341, São Paulo, SP 04038-034, Brasil. cecilioluiz@uol.com.br
}

\begin{abstract}
The aim of the article, based on field data collected from a continuing education program for primary health clinic administrators, was to analyze the functioning of a health service management strategy called "management committees". Different meanings and operational modalities emerged in the committees. Various antimonies appeared in the way the committees operate (autonomy versus heteronomy, reproduction of "instituted" versus "instituting" processes, and communicative versus instrumental reasoning), thus reflecting the level of complexity in this management mechanism. Healthcare provision per se by the clinics only appeared occasionally on the committees' agenda, which mainly focused on administrative issues. The article suggests that further research is needed on the coordinator's involvement in the field of forces constituting the management committee, besides developing pedagogical strategies to support the clinic coordinators and health teams in building the committees. The primary data were submitted to an epistemological discussion anchored in the idea of double hermeneutics, multiple validation of research results, and the relationship between theory and practice.
\end{abstract}

Health Management; Health Centers; Strategies

\section{Introdução}

A gestão colegiada, em todos os níveis da organização e em todas as organizações de saúde, tem sido adotada como o eixo de processos de gestão considerados como inovadores ou alternativos ao "modelo gerencial hegemônico", pelo menos desde o final da década de 1980, no processo de construção do Sistema Único de Saúde (SUS) no nosso país. Não seria incorreto localizar no grupo que se reuniu no Laboratório de Administração e Planejamento em Saúde (LAPA), do Departamento de Medicina Preventiva e Social da Universidade Estadual de Campinas, as primeiras formulações mais sistematizadas sobre o funcionamento dos colegiados. As formulações iniciais do grupo são marcadas pela preocupação com a melhor representação possível dos trabalhadores nos colegiados, visando à constituição de espaço coletivo de contraste, disputa e composição das diferentes visões e interesses dos atores organizacionais, na perspectiva de uma prática mais solidária, menos alienada e mais cuidadora dos usuários 1,2. Também é possível afirmar que a idéia de "gestão colegiada" desempenhou um importante papel na formulação e implementação de modos de se fazer a gestão em um conjunto importante de hospitais públicos, centros de saúde e equipes de gestão de secretarias municipais e estaduais de saúde, desde a criação do SUS. Nessa medida, a idéia de "gestão colegiada" foi sendo paulatinamente incorporada a parcelas 
do pensamento sanitário brasileiro e transformada em algo como um parâmetro para se avaliar o quanto os processos de gestão, adotados pelos vários gestores ou gerentes, eram mais ou menos democráticos ou participativos.

Fazer gestão colegiada, materializada em colegiados de gestão, em todos os níveis de decisão, formulação e avaliação de políticas de saúde e em todos os espaços de trabalho, transformou-se em uma espécie de garantia de inovação da gestão, que deveria resultar em efetivas mudanças no paradigma clássico da administração pública, com suas bem conhecidas e denunciadas mazelas de rigidez, baixa comunicação, autoritarismo, alienação dos trabalhadores, e, mais importante, na insensibilidade para com as necessidades dos usuários.

Em trabalhos anteriores 3,4,5,6, e com base em estudos empíricos, já havia sido apontado um conjunto de problemas ligados à concepção, organização e funcionamento de colegiados gestores em ambiente hospitalar. Nesses estudos, discutia-se o quanto, na prática, existia uma grande distância entre as formulações originais a respeito dos propósitos e das expectativas postas nos colegiados gestores e o que acontecia quando eles eram operacionalizados, de fato, por exemplo, nos hospitais. Centralmente, apontava-se para o fato de os colegiados não conseguirem cumprir sua promessa de democratização substantiva da vida organizacional, não serem reconhecidos pelos trabalhadores como espaço efetivo de participação e decisão e que, por conta disto, transformarem-se, em algumas situações, em simulacros das suas concepções originais. No presente artigo, são apresentadas e discutidas novas evidências empíricas das dificuldades de operacionalização de colegiados de gestão como instrumentos para a inovação da gestão, com base em estudo e observação da operacionalização dos colegiados em um conjunto de unidades básicas de saúde (UBS), complementando e aprofundando as observações anteriores, realizadas em instituições hospitalares.

\section{O contexto do estudo}

A Secretaria Municipal de Saúde de Campinas está estruturada em cinco Distritos de Saúde, responsáveis pela coordenação das sessenta UBS e outros serviços de maior complexidade. Cada UBS tem um coordenador que é um profissional de nível universitário, em tempo integral, com pró-labore específico para a função. Cada Distrito de Saúde dispõe, em média, de 11 profissionais que atuam como "apoiadores" para o trabalho dos coordenadores das UBS.
Em maio de 2005, foi iniciado o Programa de Educação Permanente (PEP) com o objetivo de propiciar um espaço compartilhado de reflexão e diálogo entre os coordenadores das UBS e outras instâncias de coordenação e apoio da Secretaria Municipal de Saúde, visando a consolidar e qualificar a atenção prestada por uma rede que vem sendo construída desde o final da década de 1970.

O PEP foi pensado baseando-se nos princípios da educação permanente que "parte do pressuposto da aprendizagem significativa e propõe que a transformação das práticas profissionais deva estar baseada na reflexão crítica sobre as práticas reais, de profissionais reais em ação na rede de serviços" 7 (p. 18).

A cada encontro, e a partir da discussão de situações concretas de trabalho e/ou de temas emergentes, a coordenação ampliada do PEP, constituída por representantes de todos os Distritos Sanitários, propõe a realização de uma "prática gerencial" pelos coordenadores; este é o núcleo operativo do PEP. Ela é uma "proposta de intervenção" do coordenador junto à sua equipe, a partir de problemas vividos no processo de gestão, e é desenvolvida com o suporte dos apoiadores distritais e de um técnico do Centro de Educação do Trabalhador de Saúde (CETS). São realizados encontros mensais que reúnem gestores do nível central da Secretaria Municipal de Saúde, os cinco coordenadores distritais, os apoiadores e todos os coordenadores da rede básica para um compartilhamento da vivência da prática gerencial desenvolvida no mês. O encontro mensal, que reúne dezenas de gerentes, torna-se uma verdadeira assembléia de todos esses atores; é a culminância de um rico processo de intervenções junto às equipes e de discussões prévias no nível de cada distrito.

\section{Metodologia}

O PEP é um processo de sístole/diástole, visando ao envolvimento do maior número de trabalhadores nas discussões, em seus locais de trabalho, nos momentos de diástole (dispersão) e grandes momentos de síntese, de reflexão compartilhada nos momentos de sístole (concentração). Tal desenho tem se constituído espaço privilegiado de observação da vida organizacional em toda sua diversidade e complexidade. A produção do conhecimento no processo de educação permanente ocorre nesses movimentos de síntese e diástole, com base no protagonismo dos atores institucionais.

A avaliação do funcionamento dos colegiados de gestão, implantados como política gover- 
namental em todas as unidades desde o começo da década, entrou na pauta do PEP a partir da discussão das dificuldades que os coordenadores têm de conduzir situações de conflito presentes no cotidiano das unidades, que parecem "transbordar" os colegiados, os quais não conseguem funcionar como espaços para encontros mais negociados e produtivos. Os colegiados de gestão aparentemente não conseguem cumprir algumas expectativas que suas formulações iniciais previam, em particular a de funcionar como espaços de negociações, composições e pactuações 1,2 . Por outro lado, não se tinha uma avaliação mais global e de conjunto, na Secretaria Municipal de Saúde, a respeito do funcionamento real dos colegiados de gestão adotados como uma de suas estratégias de gestão.

Muitos coordenadores reconheciam nunca ter parado para uma reflexão mais sistemática sobre o funcionamento do colegiado de sua unidade. Havia uma sensação compartilhada, embora de maneira um pouco vaga, de que os "colegiados não funcionavam bem" ou que "os colegiados não funcionavam como deviam funcionar". Esses eram os problemas concretos trazidos pelos coordenadores para os encontros do PEP e que orientaram a definição de uma prática gerencial, proposta pela coordenação do PEP composta por representantes de todos os Distritos Sanitários -, que consistia na realização de entrevistas com membros e não-membros do colegiado de gestão, procurando caracterizar a visão dos trabalhadores sobre seu funcionamento. Adotou-se um roteiro de questões para orientar as entrevistas: "Todos os trabalhadores conhecem o colegiado de gestão?", "Para que existe o colegiado de gestão na visão dos trabalhadores?", "Há diferenças de percepção pelo fato de ser ou não membro do colegiado de gestão?", "Há uma 'capilarização' das decisões do colegiado de gestão, ou, os trabalhadores sabem o que se passa no colegiado de gestão?", "Conhecem as decisões que ali são tomadas?", "Elas impactam em suas vidas?", "Os trabalhadores se sentem representados no colegiado de gestão?", "Qual o sentido do colegiado de gestão para a maioria dos trabalhadores?”.

Metodologicamente, pode-se dizer que os próprios coordenadores atuaram como "pesquisadores", isto é, ajudaram a construir o problema nos encontros mensais do PEP, foram a campo para a coleta de dados e reuniram-se nos seus distritos sanitários para discussão preliminar dos dados encontrados. As discussões, sínteses e novas formulações de problemas nos debates distritais foram trazidas para os encontros mensais, buscando-se outras sínteses e uma compreensão mais aprofundada dos problemas eleitos para "intervenção". Os registros das discussões desencadeadas na rede básica, a partir das questões apontadas anteriormente, constituem-se no material empírico do presente artigo. O material sistematizado e apresentado em power-point pelos coordenadores nos encontros mensais são conservados junto ao CETS da Secretaria Municipal de Saúde de Campinas. Para a elaboração do artigo, foram trabalhados os registros referentes a três encontros realizados em 2006, que tiveram como tema da prática gerencial o funcionamento dos colegiados de gestão. Anotações pessoais do autor do artigo, que participa da coordenação do PEP, realizadas durante os encontros do PEP, também foram utilizadas para compor o material empírico do artigo.

Do ponto de vista epistemológico, o artigo adota a posição de que o conhecimento que vai sendo produzido nas práticas gerenciais do PEP pode ser entendido com base na idéia da dupla hermenêutica, à qual a pesquisa social está inevitavelmente ligada, como aponta Melucci 8 (p. 33): “Não se trata de produzir conhecimentos absolutos, mas interpretações plausíveis. Os comportamentos nos dizem alguma coisa como os atores interpretam a própria ação. A pesquisa produz interpretações que buscam dar sentido aos modos como os atores buscam, por sua vez, dar sentido às suas ações. Trata-se de relatos de sentidos ou, se quisermos, de narrações de narrações”.

Também para Melucci 8 (p. 34): "O objetivo da pesquisa social não tem mais uma pretensão de explicar uma realidade em si, independente do observador, mas se transforma em uma forma de tradução do sentido produzido pelo interior de um sistema de relações sobre outro sistema de relações que é aquele da comunidade científica ou do público. O pesquisador é alguém que traduz de uma linguagem para outra. (...) Passa-se, então, da conexão linear entre hipóteses e verificação de hipóteses, que era o modelo clássico da pesquisa científica, à explicação emergente e recorrente dos processos nos quais o conhecimento é produzido através da troca dialógica entre observador e observado; a explicação não é entendida como verificação objetiva de hipóteses, mas como um processo de produção do conhecimento que se adequa progressivamente através da interação entre observador e observado".

Reforça essa reflexão, uma preocupação de Ranci 9 (p. 51) ao afirmar que "se a pesquisa social ignora ou, ao contrário, desconsidera totalmente a alteridade [a relação como os atores institucionais], ela é condenada a fechar-se em uma cilada, reduzindo-se, nos casos mais graves, a uma atividade totalmente auto-referenciada, incapaz de explorar mundos sociais e realidades inéditas".

Da mesma forma, Friedberg 10 (p. 22) afirma o seguinte a respeito do papel do pesquisador: " $O$ 
seu papel é mais modesto, e provavelmente mais dificil. Tem agora duas facetas interdependentes: por um lado, produzir um conhecimento concreto da realidade humana subjacente ao contexto de ação analisado e, por outro, assistir os interessados situando-os em relação com esse conhecimento, levando-os a tirar as respectivas conseqüências e ajudando-os, portanto, a integrá-los nas suas práticas, modificando-as. O mesmo é dizer que o impacto desse conhecimento é inseparável de uma ação de comunicação de resultados através da qual se consegue modificar a compreensão dos interessados sobre o seu contexto (...). A produção do conhecimento e a sua utilização na prática estão intimamente ligadas".

A idéia de Friedberg 10 (p. 23) de que "o impacto de uma análise organizacional é, pois inseparável do seu valor pragmático, ou seja, da sua capacidade para desencadear nos interessados a aprendizagem de um outro raciocínio sobre o seu contexto de ação", também ajuda a ilustrar a opção metodológica que orienta o presente estudo.

Pretendia-se, pois, uma metodologia de investigação que conseguisse produzir um conhecimento que fosse apropriado, imediatamente, pelos atores da pesquisa, buscando, no caso, tanto compreender os sentidos dados à proposta de funcionamento do colegiado gestor, pelo coordenador e pelos membros da equipe, como propiciar que fossem explorados novos sentidos e novas possibilidades de funcionamento para o colegiado de gestão não explorados antes.

O processo de educação permanente dos coordenadores, por meio do PEP, tem se ocupado, para além da dimensão pedagógica propriamente dita (capacitar coordenadores para a sua função gerencial), de uma dimensão de produção de conhecimento, ao tentar construir, com algum sucesso, uma nova relação entre teoria e prática, ou entre produção de conhecimento e ação.

Buscando ser coerente com a proposta pedagógica que as metodologias de educação permanente adotam, no PEP, a "teoria" que vai sendo apresentada e apropriada pelos participantes não deve ter um caráter "externo" e nem "anterior" às praticas e problemas desenvolvidos no correr do processo de aprendizado 11. Idealmente, a reflexão teórico-conceitual deve nascer junto com a prática, na forma de conceitos e reflexões que, ao mesmo tempo em que refletem a prática, devem iluminá-la, em uma relação dialética de fortalecimento e desenvolvimento mútuos. $\mathrm{Ou}$ seja, um dos desafios do PEP é a produção de conhecimento ("teoria”) necessário para iluminar as práticas que estão sendo conduzidas, de modo que o conhecimento que vai sendo produzido faça sentido para os atores envolvidos e contribua para que ressignifiquem suas práticas.
São esses os pressupostos epistemológicos e metodológicos que embasam o presente estudo voltado a uma melhor compreensão dos sentidos, possibilidades e limites dos colegiados de gestão como instrumentos de gestão nas organizações de saúde.

\section{Resultados}

Pela opção epistemológica do estudo, que explicitamos anteriormente, os "resultados" apresentados só podem ser valorizados e apreendidos no contexto institucional de sua produção e apropriação pelos atores organizacionais. Nesse sentido, e a seguir com Melucci 8, os "resultados" neste tipo de estudo devem ser vistos como uma interpretação das interpretações que os atores institucionais (coordenadores, apoiadores, trabalhadores e pesquisadores) dão para os colegiados na sua operacionalização. Mais do que isso, os "resultados" só podem ser compreendidos como novos sentidos e novas possibilidades de arranjos e funcionamento dos colegiados, produzidos no encontro entre pesquisadores/atores e que, misturando-se e turbilhonando-se nos fluxos e nas redes de relação que constituem as “organizações", vão se bifurcando em arranjos, desenhos e modos de se construírem as relações entre trabalhadores, gerentes e usuários, na singularidade de cada equipe.

Uma palavra expressa bem os "resultados" encontrados: polissemia. Para Lalande 12, polissemia é a propriedade que uma palavra possui, numa dada época, de representar várias idéias diferentes. A prática propiciou caracterizar a extraordinária variedade de sentidos que a idéia de "colegiado de gestão" assume na rede. Nessa altura, faz-se necessário um esclarecimento. Estou adotando, como faz Spink 13 (p. 45), o conceito de "sentido" articulado, de modo inseparável, ao de "prática discursiva", ou seja, como "linguagem em ação, isso é, as maneiras a partir das quais as pessoas produzem sentidos e se posicionam em relações sociais cotidianas". Dito de outra forma, "a linguagem é ação e produz conseqüências" 13 (p. 47). Portanto, os "sentidos" que os coordenadores e os trabalhadores dão à proposta de colegiados não se desvinculam do modo como eles os vivem e experimentam em suas práticas cotidianas, para além de sua formulação no plano teórico-conceitual, enquanto "idealidade".

Por outro lado, a prática gerencial em si, o ato de tomar o colegiado de gestão como objeto de reflexão compartilhada com a equipe em um primeiro momento e, depois, de forma compartilhada com outros coordenadores, permite a 
exploração de novos sentidos e novas possibilidades de intervenção dos coordenadores.

É marcada a diversidade no modo de funcionamento dos colegiados de gestão, quando as várias unidades são comparadas entre si. Da leitura do material produzido no PEP, emergem alguns blocos temáticos que permitem caracterizar as diferenças no funcionamento entre os vários colegiados de gestão: (a) os "sentidos" dados ao colegiado de gestão pelos coordenadores e pelos trabalhadores: por que são criados os colegiados de gestão, ou, para que servem os colegiado de gestão? Qual o seu poder e autonomia? Como é seu processo decisório? É um espaço consultivo ou deliberativo?; (b) a "estrutura" e composição dos colegiados de gestão: quais os critérios para a eleição dos seus membros? Quais os critérios de representatividade adotados?; (c) a dinâmica de funcionamento do colegiado de gestão: qual a periodicidade dos encontros? Qual a sua pauta de temas? Quem organiza a pauta? Como são operacionalizadas as decisões do colegiado de gestão? Quais são as fronteiras de sua governabilidade?

Na seqüência, são apresentadas, no interior de cada bloco temático, as múltiplas visões, definições e práticas dos coordenadores e dos trabalhadores, coletadas baseando-se no material empírico do PEP, para que o leitor possa ter uma idéia da polissemia com que a proposta do colegiado de gestão é entendida, apropriada e operacionalizada pelos atores institucionais. Aqui podemos ver, em sua expressão plena, o conceito de polissemia. E indicações empíricas das tensões presentes na construção do colegiado de gestão enquanto dispositivo de gestão.

\section{Os sentidos do colegiado de gestão}

Inicialmente, chama a atenção o relato, pelos coordenadores, da existência de parcela significativa de trabalhadores que afirmaram não saber o significado do colegiado de gestão, mesmo naquelas unidades que contam com colegiados de gestão há vários anos. Para muitos, o colegiado de gestão foi criado para auxiliar o coordenador de forma consultiva, na medida em que a função de deliberação seria atributo do coordenador. Alguns atribuem a função de deliberação à reunião geral da unidade. Alguns vêem o colegiado de gestão como espaço para as pessoas apresentarem suas opiniões, colaborando com as decisões do coordenador. Para outros, seria simplesmente o espaço para a transmissão de diretrizes do nível central a serem cumpridas pelo nível local, o que daria uma conotação autoritária para o colegiado de gestão. O fato de participar ou não do colegiado de gestão parece influenciar sobre o sentido que os trabalhadores dão ao colegiado. Mas há o reconhecimento, também, de que o colegiado de gestão funcionaria com uma "caixa de ressonância” ao permitir ecoar o que está ocorrendo nos bastidores da unidade.

Há unidades em que o colegiado de gestão simplesmente não funciona mais, mas há relato de uma UBS em que o colegiado de gestão teria gerenciado a unidade durante o afastamento do coordenador. Um coordenador simplesmente "aboliu" o colegiado de gestão quando teve contrariada sua decisão de implantar maior controle do livro-ponto. Hoje, prefere outros espaços coletivos da unidade como arranjos de decisão e encaminhamentos mais compartilhados.

O limite do que pode ou não "ser aberto" no espaço coletivo do colegiado de gestão aparece com freqüência. Qual o limite de confiança que o coordenador pode ter no colegiado de gestão? O quanto ele pode abrir suas limitações e dúvidas pessoais para membros do colegiado de gestão, sem se tornar seu refém?

Há uma tensão entre a percepção do colegiado de gestão como espaço democrático, de práticas solidárias, dialógicas, visando à construção de consensos em torno de um projeto para a unidade, e a percepção do colegiado de gestão como espaço duro de disputa, de imposição de projetos que "vêm de cima", revestindo-se, portanto, de um caráter mais instrumental e, onde, por conseqüência, nunca se pode "abrir tudo".

\section{A "estrutura" e composição dos colegiados de gestão}

A composição e modo de estruturação dos colegiados de gestão também são muito diversificados entre as unidades de saúde. É freqüente a ausência de candidatos ao cargo de membro do colegiado de gestão pelo simples desinteresse dos trabalhadores. Por outro lado, os interessados poderão participar por simples convite do coordenador ou por indicação dos pares. Pares entendidos tanto como os membros da mesma categoria profissional ou indicados pelas equipes de referência. No primeiro arranjo, há a avaliação de que o colegiado de gestão poderia assumir um caráter mais corporativista, isto é, o representante seria, principalmente, um porta-voz dos interesses de sua categoria profissional. $\mathrm{O}$ segundo seria visto como melhor, pois permitiria a representação dos interesses da equipe cuidadora e, por tabela, dos usuários. Foram relatadas formas de representação mista da categoria profissional/equipe. O principal problema, numa ou noutra forma de representação, é a pouca articulação entre o representante (no colegiado gestor) e os representados (demais trabalhadores). 
Freqüentemente a participação do trabalhador no colegiado de gestão está marcada pelas relações de confiança e afinidade que mantêm com o coordenador. Em algumas situações, o colegiado de gestão reflete a "coalização de poder" da unidade, constituindo-se em espaço controlado por determinado grupo, muitas vezes em disputa com outros grupos que acabam excluídos do processo decisório.

\section{A dinâmica de funcionamento do colegiado de gestão}

A pauta do colegiado de gestão parece ser, na maioria das unidades, tomada por questões do cotidiano da unidade, incluindo as escalas, discussão de substituições nas licenças, as faltas, o não cumprimento de horário, os conflitos interpessoais, e toda espécie de "assunto administrativo", como falta de pessoal, insuficiência de recurso materiais, problemas com a manutenção predial e de equipamentos etc. Há um reconhecimento de que "problemas internos" consomem a pauta, que se torna cansativa e desgastante.

A pauta muitas vezes é pactuada na hora da reunião, entre o coordenador e os membros, que priorizam os assuntos. Há assuntos que não são levados para a reunião por serem entendidos como de decisão do coordenador. As decisões tomadas são muitas vezes implementadas, mesmo com divergências nas equipes. Em alguns colegiados de gestão, as questões polêmicas são processadas antes nas equipes.

Um achado muito marcante do estudo é o fato de praticamente nenhum colegiado de gestão se ocupar de temas ligados à gestão do cuidado propriamente dita. De uma maneira geral, os coordenadores reconhecem que o colegiado de gestão não é utilizado para o planejamento e avaliação dos processos de trabalho da unidade e não consegue operacionalizar instrumentos e mecanismos mais regulares de avaliação da qualidade do cuidado prestado. As reuniões do colegiado de gestão são sempre atravessadas pelas demandas das várias instâncias do nível central da Secretaria Municipal de Saúde, sobrando pouco ou nenhum tempo para o desenvolvimento de uma pauta mais planejada, mais técnica e mais sob o controle do colegiado. Os participantes afirmam serem freqüentemente surpreendidos pelas "pautas de última hora", trazidas pelo coordenador ou não.

Os coordenadores reconhecem que é difícil a comunicação para o conjunto dos trabalhadores das decisões tomadas no colegiado de gestão. Muitos trabalhadores afirmam que simplesmente nunca sabem o que acontece nas reuniões do colegiado de gestão. Várias estratégias para me- lhoria da comunicação com os trabalhadores foram relatadas pelos coordenadores - informes na equipe de referência ou na reunião geral, uso de painel ou disponibilização das atas das reuniões para leitura dos interessados -, mas reconhecendo que conversas informais são, muitas vezes, a melhor fonte de informação sobre o que se passa no colegiado de gestão.

Representatividade e comunicação do colegiado de gestão com o conjunto dos trabalhadores são faces da mesma moeda e parecem ser algo, na percepção dos trabalhadores, mal resolvido.

As restrições de governabilidade do colegiado de gestão, em particular a rigidez sobre o que pode e o que não pode decidir, as regras organizacionais mais gerais que estruturam seu campo de decisão e até sua pauta de temas, são apontadas como justificativa para o esvaziamento e desinteresse dos trabalhadores pelo colegiado. Tal fato remete a uma dupla discussão de autonomia: do colegiado de gestão em relação aos "níveis superiores" da Secretaria Municipal de Saúde e do colegiado de gestão em relação ao coordenador. Os coordenadores reconhecem que atuam com uma "autonomia tutelada", isto é, devem respeitar limites aparentemente rígidos estabelecidos pelas normas organizacionais, do que pode ou não ser ultrapassado, embora tais limites nunca sejam bem nítidos e, freqüentemente, ultrapassados. Há coordenadores que afirmam que haveria algumas questões do âmbito da gestão que não podem mesmo ser democratizadas, de forma que o coordenador inevitavelmente terá momentos de solidão em suas decisões, tendo de arcar com ônus e bônus das decisões tomadas.

Assim, um dos aspectos mais desafiadores da implementação do colegiado de gestão seria o equacionamento da relação entre o coordenador e o colegiado de gestão, em particular o quanto ele está disposto (ou preparado) a se submeter às decisões do colegiado que contrariam sua posição pessoal e de alguma forma questionam sua autoridade. O coordenador terá de caminhar sempre na tênue zona que separa a possibilidade de uma transparência total com a equipe, da manutenção de áreas mais privadas, de reflexão e de decisão, impedindo assim uma relação plena de confiança e de diálogo entre ele e os membros do colegiado de gestão. Por outro lado, há decisões do gestor que desestabilizam (e desacreditam) o grupo exatamente por contrariarem uma decisão tomada no coletivo, deixando o representante de uma categoria ou de uma equipe desacreditado perante os seus pares. Assim, o que deve ser preservado e discutido sozinho ou com o grupo de confiança, o que deve ou não ser aberto para o 
coletivo é freqüentemente motivo de dúvida para o coordenador, inclusive para evitar, como dizem alguns, "sua desmoralização perante a equipe". Por outro lado, há reconhecimento de que há "agendas ocultas" que nunca serão abertas no colegiado de gestão.

\section{Conclusões}

O colegiado de gestão, mais do que um mero arranjo burocrático-administrativo, deve ser pensado como um arranjo institucional que assume um caráter fortemente político, devido ao fato dele se constituir em espaço onde os temas da autoridade, do poder, do controle da decisão estarem sempre presentes, de forma mais ou menos explícita. Por exemplo, o colegiado de gestão é onde o coordenador pode experimentar até que ponto está disposto ou consegue democratizar, de fato, algumas decisões que afetam a vida de todos os que trabalham naquela unidade, em particular, o quanto consegue conciliar sua autoridade legal-formal, de "chefe", com um modo de decisão mais participativo, no qual sua autoridade possa ser questionada.

O coordenador, querendo ou não, representa o governo no colegiado de gestão, na medida em que é ele que sinaliza os limites de autonomia de decisão da equipe, funcionando como "guardião" das normas, das regras e da política institucional. Por outro lado, o colegiado de gestão pode ser pensado como um grupo atravessado e constituído por várias instituições: a instituição Medicina, a instituição Enfermagem, a instituição Burocrática. Adota-se aqui o conceito de instituição como 14 (p. 177) “as árvores de decisões lógicas que regulam as atividades humanas, indicando $o$ que é proibido, o que é permitido e o que é indiferente. (...) Para realizar concretamente sua função regulamentadora as instituições materializamse em organizações [uma Secretaria Municipal de Saúde, por exemplo] e em estabelecimentos [uma unidade básica, por exemplo]" (grifo nosso). Ou seja, o colegiado de gestão constitui-se em campo fortemente estruturado por linhas de determinação e regulamentação externas, onde deverão ser cavados espaços para a construção de novas formas de relacionamento dentro da equipe.

O colegiado de gestão poderá ser visto tanto como instrumento para ampliar a democratização da gestão e a autonomia das equipes, numa perspectiva mais emancipatória, como poderá adquirir o caráter de arranjo institucional para aumento de controle e "alinhamento" das equipes em torno de diretrizes governamentais, numa perspectiva mais instrumental. Na prática, as du- as tendências conviverão, sempre, no colegiado de gestão. Uma função pedagógica importante do PEP tem sido ajudar a equipe e o coordenador a terem um pouco mais de clareza dessa tensão constitutiva da vida organizacional, e com base nessa compreensão, ser capaz de ir explorando as várias possibilidades do colegiado de gestão.

Por tudo isso é que o colegiado de gestão assume, sempre, um caráter político muito mais do que meramente administrativo-burocrático e, nesta medida, não pode ser tratado no formalismo de sua composição e funcionamento, mas nos sentidos com que é apreendido e operacionalizado pelas diferentes equipes.

Não há uma "fórmula" de colegiado de gestão. Ele não pode ser pensado como a estratégia de gestão, capaz de propiciar, sozinho, espaço institucional com potência para conciliar interesses/desejos individuais com a racionalidade mais instrumental que atravessa a organização, com sua incontornável necessidade de adequar meios (modos de se fazer a gestão do trabalho, centralmente) com os fins ou a produção de valores de uso (produzir cuidado) ${ }^{2}$. Tal constatação é agravada, nos dias de hoje, pela crescente busca por resultados e eficiência que invade a agenda de gestores da saúde.

A complexidade das relações de qualquer serviço de saúde, mesmo uma "simples" equipe de saúde da família, transborda o espaço do colegiado de gestão. A perspectiva Arendtiana 15 (p. 36) de que "o poder corresponde à habilidade humana não apenas para agir, mas para agir em concerto" implícita as formulações originais do colegiado de gestão, parece não ter valorizado adequadamente outras dimensões de poder existentes na vida organizacional 16 , seja na sua dimensão legal/formal (do tipo "topo-base”, como descrito por Weber em sua discussão sobre a Burocracia ${ }^{17}$ ) seja de disciplinamento/controle (como problematizado, entre outros, por Foucault 18,19 ), de modo que as organizações serão sempre territórios de dominação e violência. $\mathrm{O}$ projeto ético-político de construção de espaços de gestão mais solidários, "produtores de sujeitos para a reforma sanitária”, de forte base comunicativa e dialógica, de alguma forma não valorizou, em toda a sua dimensão, o poder de reprodução dessa trama de relações de poder que atravessa e constitui o colegiado de gestão.

São necessários processos pedagógicos institucionais - seja na linha proposta pela educação permanente, seja em processos de análise ou apoio institucional 2 - para que o coordenador, bem como o maior número possível de membros da equipe, reconheçam as tensões que constituem o colegiado de gestão, suas linhas de força de determinação, suas contradições e 
os interstícios de liberdade/governabilidade e possibilidade de experimentação de uma nova rede de relações na unidade. Nenhum colegiado de gestão, mesmo o que se aproxime da idealidade anunciada pelos seus formuladores como estratégia de gestão, dará conta da complexidade da vida organizacional. É necessário, portanto, ter clareza dos limites e possibilidades do colegiado de gestão enquanto instrumento de gestão ${ }^{6}$, limites dados, em outras razões, pela implicação 20 do coordenador no campo de forças constituído pelo colegiado. Por mais que ele deseje que o colegiado se transforme em espaço democrático, será sempre o "chefe" e visto como tal pelos trabalhadores que compartilham o espaço coletivo do colegiado de gestão. Por conta da autoridade legal-formal de que é investido, o coordenador nunca é um "igual”, ocupando um lugar próprio no campo de relações que constituem o colegiado de gestão.

O material empírico coletado no PEP evidencia, muito fortemente, como o colegiado de gestão, mais do que uma "fórmula" de gestão, é um dispositivo complexo, contraditório, a ser construído como política institucional. A acentuada disparidade de formação, biografias pessoais, visões de mundo dos diferentes gerentes, associados às diferentes dinâmicas da equipe resultam em grande variedade de modos de funcionamento e sentidos do colegiado de gestão, que caminha, muitas vezes, no sentido contrário ao de suas formulações originais. Dois exemplos disso são quando ele é controlado pela "coalizão de poder" da unidade para isolar grupos antagônicos, ou quando, o que é freqüente, ele se torna simples correia de transmissão das diretrizes organizacionais.

Vários sentidos contraditórios quase sempre coexistirão no mesmo colegiado de gestão, de forma tensa e inconclusiva, a depender do protagonismo do coordenador e dos trabalhadores, como tudo na vida organizacional. Cabe ao coordenador compreender esses embates de sentido, compartilhando-os da melhor forma possível com a equipe e definindo, com ela, as opções que serão adotadas.

Finalizando o artigo, retoma-se a sempre problemática idéia da validação em estudos qualitativos. No caso do presente estudo, trabalhou-se com o conceito de múltipla validação 21 . Uma primeira validação possível e necessária é aquela feita junto aos atores institucionais, ou o "publico interno" ao estudo, quando reconhecem a narrativa construída pelo pesquisador, a partir de suas próprias narrativas. A dupla hermenêutica, como define Melucci ${ }^{8}$. O importante é que não seja um reconhecimento apenas formal do quanto o texto produzido "representa", ou não, o que foi dito, mas um texto recriado e que possibilite novos impulsos e novas possibilidades de ação e de reinvenção das relações organizacionais. Um conhecimento que, produzido com base nas práticas reais, possa contribuir para a experimentação de novos modos de se produzir a organização.

Outras formas de validação são aquelas buscadas junto aos múltiplos públicos externos ao contexto do estudo, seja ele a comunidade científica que constitui o campo de saber especializado no qual ele se insere, seja aquela formada por outros consumidores desse tipo de conhecimento, em particular pelos que se ocupam das atividades de gestão e gerência dos serviços de saúde. Junto aos públicos externos, a validação visaria a obter o reconhecimento de que o autor, por adotar procedimentos metodológicos e referencial teórico coerentes com os objetivos do estudo, e utilizando de observações empíricas em determinado contexto institucional, estaria autorizado a apresentar indicações válidas para outros contextos nos quais se tem a pretensão de operacionalizar os colegiados de gestão como estratégia de gestão.

Algumas indicações, então, para finalizar o artigo: (1) o colegiado de gestão pode ser condição necessária, mas nunca suficiente para a produção de modos mais compartilhados de gestão; (2) o modo real de funcionamento do colegiado de gestão adquirirá múltiplas configurações e sentidos, a depender do contexto organizacional em que é experimentado; (3) o gerente de um serviço que adota o colegiado de gestão deve ser preparado e apoiado, por meio de processos pedagógicos apropriados - seja na linha construtivista dos processos de educação permanente, seja na linha de apoio institucional -, para lidar com sua própria implicação na organização e condução do colegiado de gestão e para que tenha a melhor compreensão possível das dificuldades e da tensões imanentes a tal dispositivo; (4) autonomia/ heteronomia 17, reprodução dos instituídos/novos processos instituintes 14, agir comunicativo/ agir instrumental 22 são antinomias, como mostra o estudo, que sintetizam, em boa medida, as tensões constitutivas que deverão ser foco de sua atenção; (5) outros mecanismos de coordenação e co-gestão, mais descentrados, ágeis e colados aos processos de trabalho poderão ter mais potência que o próprio colegiado de gestão para a reconstrução das relações na equipe, entre os quais a constituição de grupos de trabalho para enfrentamento de problemas específicos, a elaboração de projetos terapêuticos envolvendo toda a equipe para pacientes em situação de vulnerabilidades e todo e qualquer arranjo que tome o cuidado como foco de atenção e ponto de partida. 


\section{Resumo}

O artigo teve como objetivo analisar, com base em ma terial empírico coletado em programa de educação permanente de coordenadores de unidades básicas de saúde, o funcionamento de colegiados de gestão. É possível caracterizar uma marcada polissemia nos sentidos e modos de operação dos colegiados. Antinomias estão presentes em sua operacionalização (autonomia/heteronomia, reprodução do instituído/processos instituintes, razão comunicativa/razão instrumental), o que dá a dimensão da complexidade do dispositivo de gestão analisado. A gestão do cuidado apenas pontualmente entra na pauta do colegiado gestor, ocupado principalmente com questões administrativas. Sugere-se que a implicação do coordenador no campo de forças que constitui o colegiado seja objeto de análise, bem como sejam desenvolvidas estratégias pedagógicas que apóiem os coordenadores e as equipes na construção dos colegiados. O material empírico foi submetido a uma discussão epistemológica ancorada na idéia da dupla hermenêutica, na múltipla validação dos resultados da pesquisa e na relação entre teoria e prática.

Gestão em Saúde; Centros de Saúde; Estratégias

\section{Referências}

1. Cecilio LCO, organizador. Inventando a mudança na saúde. São Paulo: Editora Hucitec; 1994.

2. Campos GWS. O anti-Taylor: sobre a invenção de um método para co-governar instituições de saúde produzindo liberdade e compromisso. Cad Saúde Pública 1998; 14:863-70.

3. Cecilio LCO. Autonomia versus controle dos trabalhadores: a gestão do poder no hospital. Ciênc Saúde Coletiva 1999; 4:315-29.

4. Cecilio LCO, Mendes TC. Propostas alternativas de gestão hospitalar e o protagonismo dos trabalhadores: por que as coisas nem sempre acontecem como os dirigentes desejam? Saúde Soc 2004; 13:39-55.

5. Bernardes A, Cecilio LCO, Nakao JRS, Évora YDM. Os ruídos encontrados na construção de um modelo democrático e participativo de gestão hospitalar. Ciênc Saúde Coletiva 2007; 12:861-70.
6. Abrahão AL. Colegiado gestor: uma análise das possibilidades de autogestão em um hospital público. Ciênc Saúde Coletiva 2008; 13:95-102.

7. Haddad J, Roschke MA, Davini MC, editors. Educación permanente de personal de salud. Washington DC: Organización Panamericana de la Salud; 1994. (Série de Desarrollo de Recursos Humanos, 100).

8. Melucci A, organizador. Por uma sociologia reflexiva: pesquisa qualitativa e cultura. Petrópolis: Editora Vozes; 2005.

9. Ranci C. Relações difíceis: a interação entre pesquisadores e atores sociais. In: Melucci A, organizador. Por uma sociologia reflexiva: pesquisa qualitativa e cultura. Petrópolis: Editora Vozes; 2005. p. 43-66.

10. Friedberg E. O poder e a regra: dinâmicas da ação organizada. Lisboa: Instituto Piaget; 1993. 
11. Merhy EE, Feurwerker LCM, Ceccin RB. Educación permanente en salud: una estrategia para intervenir en la micropolítica del trabajo en salud. Salud Colect 2006; 2:147-60.

12. Lalande A. Vocabulário técnico e crítico da filosofia. São Paulo: Editora Martins Fontes; 1996.

13. Spink MJ, organizador. Práticas discursivas e produção de sentidos no cotidiano: aproximações teóricas e metodológicas. São Paulo: Cortez Editora; 1999.

14. Baremblitt G. Compêndio de análise institucional e outras correntes: teoria e prática. 3a Ed. Rio de Janeiro: Editora Rosa dos Ventos; 1996.

15. Arendt H. Sobre a violência. Rio de Janeiro: Editora Relume Dumará; 2000.

16. Cecilio LCO. A micropolítica do hospital: um itinerário ético-político de intervenções e estudo [Tese de Livre Docência]. São Paulo: Universidade Federal de São Paulo; 2007.

17. Weber M. Conceitos básicos de sociologia. São Paulo: Editora Centauro; 2005.
18. Foucault M. O panoptismo. In: Foucault M, organizador. Vigiar e punir: história da violência nas prisões. 2a Ed. Petrópolis: Editora Vozes; 2000. p. 162-87.

19. Machado R. Por uma genealogia do poder. In: Foucault M, organizador. Microfísica do poder. 25a Ed. São Paulo: Edições Graal; 2008. p. VII-XXII.

20. Lourau R. Implicação e sobreimplicação. In: Altoé S, organizador. René Lourau: analista em tempo integral. São Paulo: Editora Hucitec; 2004. p. 186-98.

21. Merhy EE. O conhecer militante do sujeito implicado: o desafio de reconhecê-lo como válido. In: Franco T, Peres MAA, Foschiera MMF, Panizzi N, organizadores. Acolher Chapecó: uma experiência de mudança do modelo assistencial, com base no processo de trabalho. São Paulo: Editora Hucitec; 2004. p. 21-45.

22. Rivera FJU. Agir comunicativo e planejamento social: uma crítica ao enfoque estratégico. Rio de Janeiro: Editora Fiocruz; 1995.

Recebido em 27/Jan/2009

Versão final reapresentada em 07/Out/2009

Aprovado em 07/Jan/2010 